\title{
EPOXY COMPOSITES BASED ON CYCLIC CARBONATES OF VEGETABLE OILS
}

\section{Hudzenko N.V., Filippovich A.Yu., Grishchenko V.K. Barantsova A.V., Busko N.A.}

Institute of Macromolecular Chemistry, National Academy of Sciences of Ukraine, 48 Kharkivs'ke shose, Kyiv, Ukraine, E-mail:gudn@ukr..net

One of the most prospective is Non-isocyanate polyurethane synthetic pathway method is the interaction of carbonized vegetable oils (CVO) and amines of different chemical nature that prevent using highly toxic isocyanates. The polymeric composite materials based on amine modifiers and epoxy resins were obtained. The physical-mechanical properties of the polymeric materials modified with amines were determined.

Keywords - cyclocarbonated vegetable oils, soy and linseed oils, epoxy-cyclocarbonate systems, aliphatic-diethylenetriamine, non- isocyanates

\section{Introduction}

Green chemistry of polyurethanes is a new promising direction of polymer chemistry and many problems in this area are still waiting for their solution. Oligomers with cyclic carbonate groups are synthesized from epoxy-containing substances. At the same time, the most perspective is the catalytic reaction of $\mathrm{CO}_{2}$ with epoxides. It is known that functionalized vegetable oils can be used as binding agents for polymer composites.

In this work carbonized vegetable oils (CVO) with five-membered cyclocarbonate groups in their structure were synthesized. Soy (CC SO) and linseed oils (CC LO) were used in the synthesis. The optimal conditions for the synthesis of oligocyclic carbonates (OCCs) such as type and concentration of catalyst, temperature and reaction time were determined.

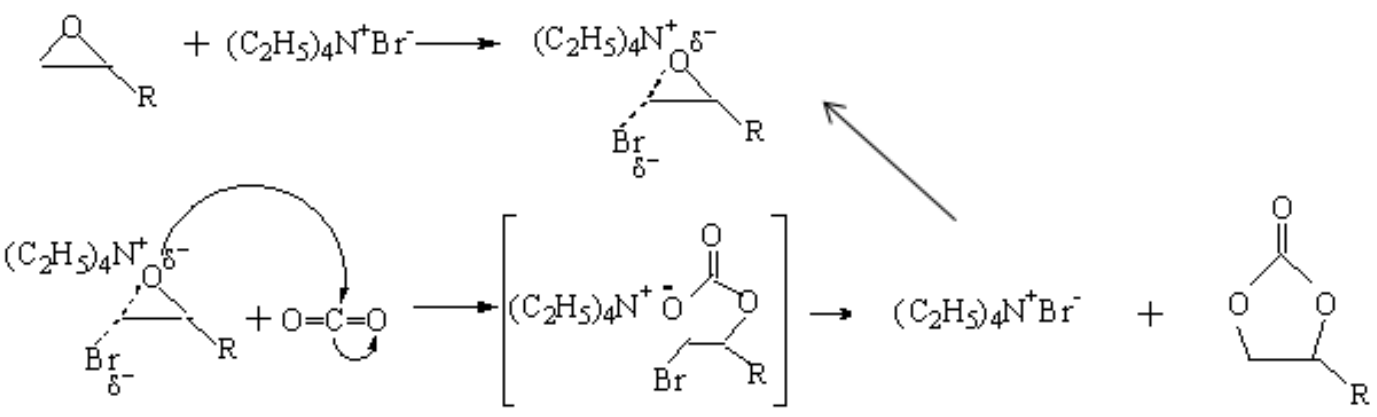

Polyurethanes were obtained (the scheme is shown below) from carbonized vegetable oils and various amine structures, without application of isocyanates:

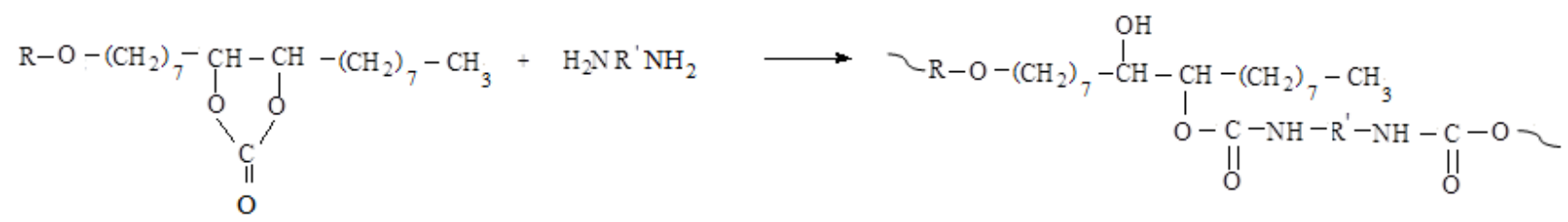

The OCCs which can be mixed unlimitedly with epoxide resin (EC) DER331 were used in modification of epoxy composites. Two methods of epoxy-cyclocarbonate systems hardening were tried in this work. In one-stage method (simultaneous mixing of all components) polyamine hardeners were added. In two-stage method the preliminary preparation of urethane amine and subsequent hardening of the epoxy oligomer were used. The kinetics of the hardening of CC SO epoxides were studied by FTIR spectroscopy. 
Table 1 Properties of epoxy composites modified by epoxidized cyclocarbonated soybean oil (CC $\mathrm{SO})$.

\begin{tabular}{|c|c|c|c|c|c|}
\hline$N$ & Epoxy composites & $\begin{array}{c}\text { Tensile } \\
\text { strength, } \\
\text { MПa }\end{array}$ & $\begin{array}{c}\text { Elongation } \\
, \%\end{array}$ & $\mathrm{Tg}, 0 \mathrm{C}$ & $\begin{array}{c}\text { Impact viscosity } \\
\mathrm{J} / \mathrm{m} 2\end{array}$ \\
\hline 1 & $D E R 331+D E T A$ & 16 & 0.6 & 93 & 14.1 \\
\hline 2 & $\begin{array}{l}(95 \% \\
D E R 331+5 \% \quad C C \\
S O)+D E T A\end{array}$ & 34 & 5.7 & 91 & 15.0 \\
\hline 3 & $\begin{array}{l}(90 \% \\
D E R 331+10 \% \\
C C S O)+D E T A\end{array}$ & 45 & 6 & 87 & 14.7 \\
\hline 4 & $\begin{array}{l}(80 \% \\
D E R 331+20 \% \\
C C S O)+D E T A\end{array}$ & 57 & 9 & 57 & 20.8 \\
\hline 5 & $\begin{array}{l}(70 \% \\
D E R 331+30 \% \\
C C S O)+D E T A\end{array}$ & 51 & 12 & 56 & 26.6 \\
\hline 6 & $\begin{array}{l}(60 \% \\
D E R 331+40 \% \\
C C S O)+D E T A\end{array}$ & 42 & 9 & 53 & 28.6 \\
\hline
\end{tabular}

It is shown that modification of CC SO epoxides leads to a significant increase in tensile strength and elongation of samples (Table 1). The dependence of tensile strength and compressive strength of polymers on the ratio of the EC and the CC SO has an extreme behaviour for the investigated amines. A significant increase in the impact strength of composites (impact fracture toughness increases for some systems by 6-8 times) is common to all amines (aliphaticdiethylenetriamine (DETA), alicyclic, aminoacids, polyamides).

\section{Conclusion}

Changing the types of amine curing agent gives possibility to change the kinetics, mechanical and technological properties of epoxy composites. Modification of epoxy CVO leads to decrease of glass transition temperature $\left(\mathrm{T}_{\mathrm{g}}\right)$. Significant decrease in $\mathrm{T}_{\mathrm{g}}$ is observed for specimens which contain from 20 to $40 \%$ of CC SO. 